\title{
The Diffusion of Flexibility: Estimating the Incidence of Low-Regulated Working Conditions
}

I Michael Allvin'

PhD in psychology and associate professor of sociology at the Department of Sociology, Uppsala University

I Christin Mellner

PhD in psychology, researcher and lecturer at the Department of Psychology, Stockholm University

\section{Fredrik Movitz}

PhD in sociology, researcher and lecturer at the Department of Sociology, Stockholm University

\section{Gunnar Aronsson}

PhD in psychology and professor in work and organization psychology at the Department of Psychology, Stockholm University

\begin{abstract}
The purpose of this study is to determine the actual occurrences of flexible working conditions and to demonstrate an instrument for their assessment. Flexibility is discussed as a concept and defined in terms of deregulation of work, and a corresponding increase in self-government and ambiguity. Using empirical data from a national survey of the Swedish labor force, the results show that almost half (47\%) of the jobs on the Swedish labor market can be characterized as low, or even unregulated. This means that almost half of the Swedish work force is subjected to working conditions involving a nonnegligible requirement for self-government.
\end{abstract}

\section{KEY WORDS}

Deregulation / flexibility / labor market / organization / work / working conditions

\section{Introduction}

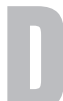
uring the past thirty years, an increasing number of changes have taken place in the labor market in Sweden and in many other Western countries. The service industry has expanded to become by far the largest employer in the OECD area (OECD, 2008). Large industries have cut down on or outsourced much of their labor- and capital-intensive production. The proportion of blue collar jobs involving manual labor is currently estimated to make up only $25 \%$ of the Swedish labor force (SCB, 2008). The rapid and growing impact of information and communication technology, along with the increased importance of knowledge-based goods and services, has boosted the competence requirements, thereby adding to the general increase of knowledge-intensive

\footnotetext{
${ }^{1}$ Michael Allvin, E-mail: michael.allvin@soc.uu.se, Department of Sociology, Uppsala University, Box 624
} 
work on the labor market (Burton-Jones, 1999; Castells, 1996; Cortada, 1998; Paganetto, 2004; Powell \& Snellman, 2004). In addition to all of these, there is the general trend in organization and management toward decentralization, entrepreneurship, and flexibility that has increased the demand for self-sufficiency and service awareness within organizations and among workers regardless of business or trade. Taken together, these changes involve a considerable remodeling of the conditions for work.

Perceived in more general terms, the transformation of the labor market should come as no surprise. It has been predicted and discussed since the early 1960s. The epithets are well known, even outside of academia: postindustrial society, consumer society, information society, etc. Even in the vocabulary of organizational theory, these changes have been thoroughly examined and responded to. Flexible organization, competent organization, postbureaucratic organization, knowledge and service management are just some of the conceptions and foci raised to meet the challenges of today. On the work and workplace level, however, it is a different matter. Even if the transformations have been just as evident here, they are conspicuously absent in the discourse on work, its administration, theories, and research.

We still speak of work in terms relating to the traditional conditions that dominated labor for the better part of the last century. More importantly, the implicit conception of work determining the administrative systems and practices of the welfare state reveal a standard that may no longer be valid for many jobs. Old-age pension and unemployment compensation, for instance, presupposes the standard of full-time employment. Restriction of Working Hours Act, Compulsory Holidays Act, and overtime payment policy presupposes regular office hours. Work environment regulations, occupational injury insurance, and labor market statistics presuppose a regular workplace. Safety precautions, disciplinary and evaluative measures, along with a substantial part of labor law, presuppose standard operating procedures as well as a binding awareness of them. Professional inclusion, union membership, and legal accountability presuppose a delimited area of responsibility.

In this paper, we will examine the organizational conditions for work and, using empirical data from a national survey of the Swedish labor force, demonstrate a widespread use of flexible conditions, leaving less than a sixth of the jobs on the Swedish labor market with working conditions associated with traditional jobs. Instead, lowregulated and boundaryless jobs, that is, jobs with various degrees of flexible working conditions, are dominating the labor market.

We will begin by dissociating ourselves from the prevailing theoretical discourse on flexibility as a paradigmatic transformation of labor. We will then go on by adopting a more empirical approach, treating flexibility as an uneven but de facto deregulation of traditional working conditions.

\section{The postulation of flexibility as a rational and coherent program}

What do we mean, then, when we speak of flexible jobs, or flexible working conditions? Let us first observe the fact that the conception of flexibility has been, and perhaps still is, a matter of dispute. The conception and investigation of flexibility is very much marked by this dispute, even more so because it has never really been resolved. Instead, it has fueled, but also narrowed the enquiries in the subject. 
The dispute was initially provoked by the indiscriminate and rhetorical use of flexibility in, above all, management literature. The rhetoric painted a picture of working conditions and the labor market as being in a state of transition, from a politically controlled system to an open market. Embracing this paradigmatic transformation, it also made promises for the future, giving hope of increased empowerment, creativity, commitment, employability, and entrepreneurship (e.g., Handy, 1984, 1989; Kanter, 1983, 1989; Peters \& Waterman, 1982). These lofty promises found their practical form in some early reports produced by the Institute of Manpower Studies (now the Institute of Employment Studies) in England, authored by John Atkinson (1984, 1986). In these reports, Atkinson (and Nigel Meager, who coauthored the second report) outlined a conceptual framework for the "flexible firm".

The promises of flexibility, as well as their more tangible form in the flexible firm, were vigorously criticized for proposing a neoliberal agenda, involving major transformations of public policy and industrial relations (Pollert, 1991; Wood, 1989). Although Atkinson in his defense later claimed that the model of the flexible firm was not meant to be taken prescriptively or descriptively, it was persistently criticized on both accounts (Legge, 2005, Ch. 5).

Although itself ideologically motivated, the critique was not leveled predominantly at the ideology behind the claims of flexibility. Instead, its chief aim was to invalidate the promises of flexibility. Several studies claimed that the rhetoric of flexibility was just that, empty rhetoric, and that "out there" nothing much had really happened (e.g., Wood, 1989). Other studies set out to show that the conditions for work under flexibility were predictably worse. In both cases, the critique presupposed a conceptual model of flexibility, outlining it as a coherent strategy and a prescription for a paradigmatic transformation of labor. So, in order to explicitly disprove the consequences of flexibility, the critique had to implicitly accept the conception of it as a coherent framework.

Critical studies, subsequently, called attention to the deteriorating working conditions following many of the transformations predicted by the flexibility model. A flexible work organization does, for example, not only generate empowerment and creativity but also, and perhaps primarily, result in work intensification (Burchell et al., 2002; Green \& McIntosh, 2001; Saloniemi \& Zeytinoglu, 2007). And, rather than encouraging commitment and loyalty, employment with a flexible corporation is liable to end in stress and alienation (Schieman et al., 2006; Sennett, 1998). It has, furthermore, been pointed out that flexibility is essentially a formidable strategy for rationalization, involving both downsizing and outsourcing (Harrison, 1994; Harrison \& Kelley, 1993). A flexible labor market may, correspondingly, be described as a program for the casualization of labor (Anderson et al., 1994; Kalleberg et al., 1997). And, instead of cultivating entrepreneurship, a flexible labor market may, just as aptly, be described as a commercialization of identity (du Gay, 1996).

Unfortunately, the implicit acceptance of flexibility as a prescription for a paradigmatic transformation of labor delimited the interpretation of the results by reducing them into arguments within a fruitless pro-con discourse. As a consequence, there is a whole branch of flexibility studies that have, explicitly or implicitly, been devoted to the review, critique, defense, evaluation, complication, or testing of this framework (e.g., Furåker et al., 2007; Hudson, 2002; Kalleberg, 2001; Kelliher \& Riley, 2003; Procter et al., 1994; Vallas \& Beck, 1996). 


\section{The many faces of flexibility}

Meanwhile, and in most cases independently of this theoretical dispute, extensive evidences of changing working conditions have been accumulated (e.g., Appelbaum \& Batt, 1994; Holman, 2003; Osterman, 1994). The studies behind these evidences do not necessarily refer to their object of study as part of a coherent strategy for the achievement of corporate flexibility (Hakim, 1990). Many of them have a different agenda altogether.

In the 1980s, the question of flexible working hours, for instance, was being raised in Sweden and elsewhere. The main reason for this was the problem of work-family balance experienced by many workers, and not only women as traditionally suggested (Jacobs \& Gerson, 2001). "Flextime" was considered a more satisfactory way to deal with this, than merely having to work part-time. As a consequence, the use of flextime increased substantially, mostly among white collar jobs (Becker \& Moen, 1999; Briscoe, 2006). This did not mean that part-time employment decreased, however.Part-time employment, voluntary as well as involuntary, has increased since the 1980s, as has the use of unpaid overtime and shift-work (OECD, 1998).

Another work form, which was initially discussed in relation to transportation and urban planning, is the possibility to work outside of the office. The expansion of the Internet in the 1990s made home work fashionable, an environment-friendly alternative, and a means to balance work and family requirements (Jackson \& van der Wielen, 1998). The use of telework was offered as, among other things, a tool for attracting qualified workers to remote office locations (Qvortrup, 1998). As a consequence, the use of telework increased in general, and among larger companies in particular. In a survey by Statistics Sweden from December 2008, 90\% of the companies with 500 or more employees reported a regular use of telework (www.scb.se). Following the increased attention, several studies have subsequently pointed to the more problematic aspects of telework, such as job spillover (Haddon, 1998; Mirchandani, 1998), professional isolation (Cooper \& Kurland, 2002), the vague legal situation (Bruun \& Johnson, 1995), as well as research, organizational, and managerial problems (Bailey \& Kurland, 2002; Cascio, 2000; Chapman et al., 1995).

Independently of these trends, there is also an increased "projectification" of organizations and work that have made teams the basic unit of production (Midler, 1995). Projects are no longer just large-scale and long-term development programs mainly used within technical industries; they are also an increasingly common work form for achieving even lesser objectives within a variety of industries and within otherwise functionally organized companies (Ekstedt, 1999). The increased use of projects and project-like work forms involves a shift from standard operating procedures to more goal-oriented, situation-sensitive, and provisional performance (Lundin \& Söderholm, 1995).

Furthermore, in industries that rely heavily on projects, many employees move between different projects more or less independently of organizational boundaries (Arthur, 1994). They may perform the same tasks while collaborating in a variety of social constellations. The collaborations within different projects may even constitute their entire social environment at work. For them work is situation specific and performed in relation to a professional network, rather than routinely provided through a functional hierarchy. This is a familiar situation to most self-employed, freelancers, and consultants. These conditions are also to be found within industries like development of Information 
and Communications Technology (Carnoy et al., 1997; Saxenian, 1996), filmmaking (Jones, 1969; Storper, 1994), fashion (Neff et al., 2005), publishing (Ekinsmyth, 2002), and of course staffing (Barley \& Kunda, 2006).

The different conditions of work that we have described above are just a few examples of relatively new work forms. Comparing the different work forms is not a matter of course, however. They do not necessarily have anything to do with each other. They may not even coincide with each other. The different conditions are not necessarily historically and geographically coordinated. Their presence varies between industries, organizations, and jobs. They also vary in proportion, intensity, and significance. Even the motives for proposing them vary.

\section{Flexibility as deregulation}

As we have seen in the critical discourse of flexibility, it has consistently been defined as a rational strategy. As such, it may involve the external market strategy of a firm or the internal industrial relations strategy. Flexibility is in both cases seen as a property of actions following a predetermined rationale. Flexibility is consequently understood as a capacity of both firms and people as rational agents.

As we can see, however, the various manifestations of flexibility involve the introduction of working conditions conformed to specific circumstances, rather than to a comprehensive rationale. Furthermore, introducing these working conditions typically changes the regulatory conditions of work. Within their respective and limited scope, the specific requirements for work are no longer prescribed by the organization. Within the limited span allowed for flextime, for instance, the time for work is not determined by the organization. Within the range of the agreement for telework, whether formal or informal, the place for work is not determined by the organization. The same can be said for the performance of work within a team or project, or the collaboration within a professional network. We can therefore say that the introduction of these working conditions involves a deregulation of the conditions for work, at least with reference to the regulated conditions that preceded their introduction.

In an organization, the activities of people are regulated. That is, in fact, what an organization is. It consists of and relies on the methodical and often repetitive behavior of people. People, on the other hand, are part of an organization insofar as they do certain things in particular ways and report to specific other members of the organization. In other words, they are part of an organization insofar as they follow the rules of the organization. Even so, we rarely think of organizations and work in terms of individual rules and regulations. Since we sign up to and get paid for following all of these rules as one, we tend to accept them as a package deal, as a job (Powell, 2001). Together they make up the situation that we enter into as workers.

The combined effects of all these rules and regulations make modern organizations probably the most heavily regulated settings that we encounter in everyday life (Katz \& Kahn, 1978). This means that the work situation within a normal and relatively large organization may be perceived as, what Karl Weick (1996) following Walter Mischel (1977) has called, a "strong" situation. Strong situations are situations that "lead everyone to construe the particular events in the same way, induce uniform expectancies regarding the most appropriate response patterns and require skills that everyone has to 
the same extent" (ibid, p. 347). When dealt with, a strong situation will, consequently, reduce behavioral discretion and prompt conformity. The opposite of strong situations is "weak" situations, which are situations that "are not uniformly encoded, do not generate uniform expectancies concerning the desired behavior, do not offer sufficient incentives for its performance, or fail to provide the learning conditions required for successful genesis of behavior" (ibid, p. 347). A weak situation will increase not only behavioral discretion and variation but also ambiguity and uncertainty.

The deregulation of the different working conditions described above may not necessarily be enough to create a "weak" situation, but one by one the deregulations do make their respective situations weaker. When added together, they will combine to reduce the cues and expectancies within the situation, and subsequently increase the discretion and ambiguity. As a consequence, such a reduction of regulations will also increase the flexibility in work. We can, therefore, identify flexibility in work, not by a particular model, nor by its rhetorical claims, its beneficiaries, or particular consequences, but by the weakness or openness of the situation and the corresponding increase of choice and ambiguity.

With such a framework, we would like to dissociate ourselves from the limited scope of the flexibility debate, while still acknowledging the validity of the more empirical arguments made by both sides.

\section{Methods}

In order to investigate these jobs and their consequences for people, a research program called Boundaryless Work was started in 1998 at the National Institute for Working Life in Sweden. The research program was exploratory and proceeded with a series of case studies studying the forms, variations, and consequences of the working conditions thought to result from new technologies and the so-called new economy. The different cases all included working conditions that in one way or another might be labeled flexible. The principal effect of these conditions was that they shifted the responsibility for the planning, performance, and consequences of work from the structural arrangements for work previously handled by organizations on to the worker, essentially making the individual accountable for the work that he/she does.

\section{Operational definitions}

In order to assess working conditions with different degrees and types of regulations, an instrument has been constructed involving four variable dimensions of work: working time, working space, performance, and collaboration at work. The four variables are similar in the sense that they assess the extent to which the respondent can regulate and delimit the work himself/herself, the assumption being that an increase in self-imposed rules and limitations presupposes a corresponding decrease in externally prescribed rules and limitations. When a respondent is able or demanded to regulate and delimit his/her work to a large extent in one of the dimensions, that dimension is regarded as not being regulated. And, vice versa, when a respondent claims to be unable to regulate and delimit his/her work in one of the dimensions, that dimension is considered to be regulated. 
The regulation of working time is consequently assessed by asking the respondents to what extent they have the possibility to decide for themselves when, during the day, week, and year, respectively, to perform her work. If the respondents answer that the decision is entirely up to them, the working time is taken as being not regulated. A similar question is directed to the dimension of space.

The performance dimension concerns the planning of the labor process, more specifically what discretionary power is left to the worker. The variable assessed, then, is what is sometimes referred to as job decision latitude (Karasek \& Theorell, 1990; cf. also Hacker, 1986). The question asked is to what extent the respondents plan, in the short and long range, the work themselves.

The dimension regarding collaboration at work concerns the hierarchical regulations of work, more specifically the powers left to the worker to choose their informers and collaborators for a specific task or assignment. In other words, whether they are restricted to the competences and functions specified and supplied by the organization, or if they can decide to transcend the boundaries of the workplace, division, or even organization, in search of collaborators that can help them get the job done.

Thus, unregulated conditions of work are less likely to involve regular working hours, a fixed place for work, standardized operating procedures, an unambiguously defined area of responsibility, a clear chain of command, and provisions of collaboration, while high-regulated conditions of work are more likely to involve such conditions.

The regulation in these four dimensions-time, space, performance, and collaboration-is thought to be logically independent of each other. They may, for instance, involve the opportunity to choose working hours while still being confined to a specified workplace, and vice versa. Being logically independent means that regulation in one dimension does not in principle presuppose a regulation in another dimension. This allows us to treat a job that is regulated in one dimension as comparable to other jobs that are unidimensionally regulated, regardless of which dimension we are talking about. The variation between different jobs then comes not from whether a specific dimension is regulated or not, but from how many of the dimensions that are. We may therefore treat the number of dimensions in which one is regulated, or the "regulation level," as a variable in itself. We can subsequently consider a job (high) regulated if the working conditions are regulated in all four dimensions. A job is low regulated if the working conditions are not regulated in two or three dimensions. If the working conditions are not regulated in any of the four dimensions, we consider the job to be unregulated.

\section{Participants}

In 2005, a questionnaire was administered to a randomly selected sample representing the working population in Sweden between ages 21 and 65. In order to obtain a sufficient number of employers, a stratified sample was used. Thus, a random sample of 1,000 individuals was drawn from those that were classified as employers, including self-employed freelancers, in Statistic Sweden's databases. The response rate for the total sample of 4,000 individuals was 2,731 (68.3\%), out of which $600(22 \%)$ were employers and 1,889 (69.4\%) employees. Individuals who, at the time of the data collection, reported not having a job or a business of their own during the past six months, for instance, people who were unemployed or on parental or sick leave or students (in total 
242 individuals), were informed that they did not have to fill out the questionnaire. The analyses are thus based on 2,489 individuals. Of these 1,328 (53\%) were men and 1,161 $(47 \%)$ women. Mean age for the responding sample was 44.57 (SD 10.96) years. Dropout analysis showed no significant differences in demographic background variables between respondents and nonrespondents.

\section{Construction of the work regulation index}

The level of regulation was investigated using a total of six questions on 4- or 5-point scales to cover the four dimensions. A work regulation index was constructed in two steps. First, the variables included in each dimension were added and then dichotomized. Respondents are thus coded as either regulated or not within each dimension. This is admittedly a considerable reduction in information as compared to using the actual variable scores, but something we view as justified since it better serves the main purpose of this study: to present an overview of the work regulation incidence within the working population. Second, the results for each dimension were added together, creating an index for each individual, representing the number of dimensions in their work that are regulated.

\section{Results}

The results are presented in five sections. In the first section, the proportion of all workers (employees and employers/self-employed) that are regulated in a particular dimension is presented. In the second section, results are presented showing the proportion of workers regulated in numbers of dimensions, i.e., the regulation level. In the third section, differences between employees and employers/self-employed are presented. In the fourth section, comparisons are made between different sectors and regions. The fifth and final section presents comparisons between levels of regulation and economic rewards.

\section{Incidence of regulated working conditions by dimensions}

The findings show that $59 \%$ of workers had jobs that were regulated in time, $74 \%$ in space, $20 \%$ in the performance, and $80 \%$ in the collaboration dimension. We thus see that a majority of workers still have jobs that are regulated in each of the dimensions, except for the performance dimension where only $20 \%$ state as being regulated.

\section{Incidence of regulated working conditions, i.e., regulation level}

In the next step, combinations of the dimensions were investigated, more specifically, in what proportion employees are regulated in the dimensions taken together. For the general labor market (Table 1), the results show that a sixth $(16 \%)$ were regulated in all of the four dimensions constituting the work regulation index, i.e., time, space, 
performance, and collaboration. Almost two-fifths of the workers (39\%) were low regulated. That is, being regulated in one or two of the four dimensions, with no consideration taken to which of the dimensions that were concerned. Finally, only a twelfth $(8 \%)$ reported no regulation in the four dimensions. In other words, their work was completely unregulated.

Table I Comparing the different proportions of work regulation levels between employees and employers (percent, unless otherwise specified).

\begin{tabular}{lcccc}
\hline Level of regulations & $\begin{array}{c}\text { Total } \\
(\mathrm{n}=2,216)\end{array}$ & $\begin{array}{c}\text { Employees } \\
(\mathrm{n}=1,761)\end{array}$ & $\begin{array}{c}\text { Employers } \\
(\mathrm{n}=455)\end{array}$ & $\begin{array}{c}\text { Annual } \\
\text { salary }(€)\end{array}$ \\
\hline Unregulated & 8 & 7 & 29 & 35,902 \\
\hline Reg. I dim. & 17 & 16 & 42 & 30,184 \\
\hline Reg. 2 dim. & 22 & 22 & 17 & 27,185 \\
\hline Reg. 3 dim. & 37 & 38 & 10 & 23,997 \\
\hline Reg. $4 \mathrm{dim}$. & 16 & 17 & 2 & 21,373 \\
\hline Average reg. & 2.4 & 2.4 & 1.2 & \\
\hline
\end{tabular}

* Average number of dimensions that are regulated.

\section{Employee-Employer Differences}

Employees were found to experience higher levels of regulation as compared to employers (Table 1). On average, employees were regulated in twice as many dimensions as employers. Comparing business owners that have employees with those that have no employees (e.g., self-employed and freelancers), it was found that business owners with employees were on average regulated in 1.4 dimensions, whereas business owners without employees were regulated in 1.1 dimensions. This is mainly because business owners without employees more often than those with employees are less regulated in time and space.

Table 2 Comparing average regulations for employees in private and public sector. Public sector further divided in government, county, and municipal level.

\begin{tabular}{lccc}
\hline Sector & Men $(n=856)$ & Women $(n=844)$ & All employees $(n=1,700)$ \\
\hline Whole labor market & 2.2 & 2.6 & 2.4 \\
\hline -Public sector & 2.1 & 2.7 & 2.5 \\
\hline -Government & 2.0 & 2.5 & 2.2 \\
\hline -County & 2.1 & 2.7 & 2.7 \\
\hline -Municipal & 2.2 & 2.9 & 2.6 \\
\hline -Private sector & 2.2 & 2.5 & 2.3 \\
\hline
\end{tabular}




\section{Sector and Regional Differences}

Given that work regulation to a considerable extent is dependent on the type of job being performed, it is likely that work regulation will differ between sectors and regions, due to the uneven geographical distribution of sectors. Average work regulation in different sectors was analyzed in two dimensions. First, comparisons were made between the public and private sector (Table 2). Second, comparisons were made between different sectors based on their area of business, irrespective of whether the business was publicly or privately owned (Table 3 ).

The data show that in the private sector, $9 \%$ of workers were unregulated, $42 \%$ were low regulated, and $49 \%$ were regulated in three or more dimensions. In the public sector, $5 \%$ were unregulated, $35 \%$ were low regulated, and $60 \%$ were regulated in three or more dimensions.

There were, however, significant differences within the public sector, with government workers having an average regulation comparable to the private sector, while county workers, which in Sweden mainly consist of health care workers, have a considerably higher average, even higher than municipal workers, e.g., education, child care, and elderly care. Not surprisingly, women had jobs that consistently were more regulated than men's.

In order to study differences in work regulation between various sectors, a broad categorization of ten sectors was used. This categorization was in turn based on the original, finer-graded categorization constituting 26 sectors making up the Swedish labor market and used in official statistics (www.scb.se). The largest sectors are health care $(21 \%)$, industry and production $(17 \%)$, and business services $(15 \%)$, where the latter is the sector growing the most during the past ten years (Arvidsson \& Ekstedt, 2006). Not surprisingly, when men and women were analyzed separately, the largest group of males was found in the industrial sector $(25 \%)$, whereas health care was the most common sector for work among women $(35 \%)$.

When comparing the degree of work regulation in different sectors, it differed significantly (chi square 275.17 , df $36, \mathrm{p}<0.000$ ). As can be intuitively expected, and as has been shown in numerous previous studies, regulation is highly related to the prevalence of Taylorist and Fordist modes of production: the auto industry and health care sectors having the highest levels of regulation, whereas IT consultants and researchers as well as direct service to small- and medium-sized enterprises and those being self-employed having the lowest levels of regulation. As can be seen, health care was the most regulated sector, whereas business service was the least regulated.

Given the different levels of regulation between sectors, and the fact that the size of sectors differs regionally in Sweden with, e.g., almost half of business services being located in Stockholm and half of raw produce in rural areas, the levels of regulation also differ between regions. Average levels of regulation for workers in major cities (Stockholm, Gothenburg, and Malmoe) were 2.2. In medium-sized cities, the level was 2.3, in smaller towns 2.4 , and in rural areas 2.5.

\section{Regulation and Economic Rewards}

For employees, having regulated jobs is associated with receiving less economic rewards for the work that is carried out (Table 1). The results show that employees that are 
Table 3 Average regulation by sector $(n=2.329)$.

\begin{tabular}{ll}
\hline Sector & Average regulation \\
Business services*** & 1.9 \\
\hline Construction & 2.1 \\
\hline Other services**** & 2.1 \\
\hline Infrastructure, maintenance & 2.3 \\
\hline Retail, hotel, and restaurant & 2.4 \\
\hline Raw produce & 2.4 \\
\hline Education & 2.4 \\
\hline Transport, communication & 2.5 \\
\hline Industry & 2.5 \\
\hline Health care & 2.6 \\
\hline ****Business services" include activities such as office cleaning and staffing, but also bankers and financial services, research \\
and development within, e.g., pharmacological companies or in collaborations with universities, and jobs related to infor- \\
mation technology such as IT consultants. \\
******Other services" include, e.g., hair dressers, artists and undertakers.
\end{tabular}

regulated in all four dimensions receive substantially lower salaries than those that are regulated in fewer dimensions, and merely $60 \%$ of the average annual salary of those having unregulated working conditions.

\section{Discussion}

As can be seen from the results, most jobs are regulated in the four investigated dimensions, the exception here being the performance, or planning, of labor where only $20 \%$ claim to be regulated. ${ }^{1}$ The regulation is also progressive, again with the exception of the performance dimension, in the sense that time has the lowest proportion of regulations while collaboration has the highest. So, when simply looking at the work regulation one dimension at the time, the jobs of the Swedish labor market seem to be thoroughly regulated, and in a fairly traditional manner.

Taken together, however, the regulation within the different dimensions presents another picture. Only $16 \%$ of the jobs are regulated in all four dimensions, while $47 \%$ are low- or unregulated. Even though most employers have jobs that are substantially less regulated than employees, the general proportion between regulated, low- and unregulated jobs remains the same for employees after subtracting the employers.

When trying to pinpoint these jobs on the labor market, the results display a clear variation among different sectors. Even though all levels of regulation are to be found within all sectors, the high-regulated jobs more often occur among the manually dominated labor of industry and health care. Low- and unregulated jobs, on the other hand, more often occur within business services, construction, and other services. Just as these sectors, low- and unregulated jobs are more prevalent within or in the immediate vicinity of larger cities.

The low- and unregulated jobs are, furthermore, male dominated, even if we take into account the fact that they are located within male-dominated sectors. They are also, on average, better paid than high-regulated jobs. 
The image of the low- and unregulated jobs that emerge through this study is, consequently, fairly consistent with the results of existing case studies. These are wellpaid, male-dominated white collar jobs that are mainly located in big cities and within the expanding service sector, in particular within the more knowledge-intensive services employed by business. The results are also consistent with the critique often leveled at many of these case studies, a critique arguing that unregulated jobs may have a high profile in the ongoing debate, but that they are atypical in real life. An illustrative example would be consultants, or architects. These are well-known jobs, but their actual occurrence within the labor market is limited. Our results fittingly show that only $8 \%$ of the work force-7\%, if the employers are excluded-report having jobs that are entirely unregulated.

The fact that our results corroborate the general impression made by earlier case studies, as well as the one made by their critics, validates the claims made by the instrument and index used in the study. The instrument seems to be measuring the very phenomenon that is the object of the debate. These claims are further substantiated by the result comparing employers with employees. For the employees, the level of regulation descends gradually toward the unregulated end of the spectrum, while the picture is more or less inverted for the employers.

This result is consistent with a managerial responsibility that, by its very nature, is difficult to combine with a highly regulated job. Such a responsibility is, on the other hand, not completely disconnected from the "here and now" of the workplace since it is tied to the condition of the labor force that it is set to manage, as demonstrated by the gradually ascending level of regulation. And, as the result shows, employers without employees (self-employed) are considerably less regulated than employers with employees.

Hence, rather than delivering any surprising information about the qualitative characteristics of low- and unregulated jobs, these results go an appreciable way to validate the claims of the instrument. This mutual benefit of corroboration between other more ideographic studies and this instrument is, however, not the most important result from this study. The most important and striking result is, rather, the extensive prevalence and diffusion of nonregulated working conditions.

Rather than merely identifying and isolating flexible jobs as such, in order to prove or disprove their presence on the labor market, this study points to the irregularities and dispersion of flexibility as a phenomenon. Flexibility is approached as a matter of degree and something that may be found everywhere, although in varying proportions. Along with unregulated we may thus also speak of low-regulated jobs, in which the worker is required to be partly, or semi-autonomous. Viewed in this way, the labor market becomes covered with nonregulated working conditions, even if nonregulated jobs are fairly rare.

\section{Deregulation and reregulation}

When Walter Mischel formulated the distinction between strong (or powerful) and weak situations, he was addressing an issue within the psychological academic community of whether it is the characteristics of a situation or of a person that determines the behavioral outcome, in psychological terminology simply abbreviated as "state or trait". When organizational scholars, like Karl Weick (1996), invoke the same distinction some 
twenty years later, it is as an argument for a postbureaucratic vision anticipating the demise of functional regulations. Since modern organizations no longer provide sufficient and uniform expectations, the argument goes, but rather confront the individual as weak situations, personal dispositions will "shine through," allowing learning, careers, and organizations to increasingly be shaped by expressions of personality and individual differences (Bell \& Staw, 1989).

Defining flexibility, as we do here, in terms of deregulation may give a similar impression of a decrease in regulations and a corresponding increase in freedom of action and choice. However, even though organizations presuppose regulated activity, deregulating the organization does not necessarily result in nonregulated activity. Rules and regulations are not the opposite of action and choice, in the sense that the first are objective restraints while the latter are subjective expressions. Rules and regulations are not objective in and of themselves.

They acquire objective features only insofar as they are acted upon. And, action and choice are defined as such only insofar as they are rational, and hence rule governed. We may therefore conclude that even though rules/regulations and action/choice may not be reducible to one another, they certainly presuppose each other. In any case and for our purposes, it is enough to recognize that regulations and action do not exclude one another and that, consequently, a deregulation of organizational structure will not necessarily result in its presumed opposite, a nonregulated activity. Nor does it have to involve an increased reliance on personal dispositions, temperament, or personality. This means that a deregulation of jobs and organizations will not primarily result in increased opportunities for individuals to express their individuality. Instead, the individuals will simply be forced, directly or indirectly, to redirect their attention. Action and choice will, in other words, be directed toward other rationales for governance, whether internal or external to the individual.

There are at least three different types of rationales that may complement or replace the functional organization. The first is intraindividual and involves the individual's professional competence. Professional competence may be practically as well as theoretically acquired. In either case, it constitutes a rational for action. In a weak situation, in which the cues, expectancies, and incentives for performance are insufficient, the situation is continually in need of interpretation. In order to work out a rational, with only limited and perhaps even conflicting information available, the individual will have to interpret the situation by drawing on more abstract mental models acquired through training (Doyle \& Ford, 1998; Rasmussen, 1986). A situation that supports several and conflicting interpretations is essentially ambiguous. As such, it will resist the employment of a decided mental model, leaving the individual to use what strategies he or she can come up with in order to cope with or make sense of the situation (March, 1978; Weick, 1995).

The second type of rational is provided by the extraorganizational conditions. As we have already said, dismantling the rules and regulations of work does not necessarily increase the individual's freedom. It will, however, break up the boundaries of the job or organization.

Rather than facing the relatively ordered conditions inside the organization, the individual will then be confronted more directly with requirements that are external to the job and the organization, such as market forces, business, trade, technical, and social requirements. These are requirements that would otherwise have been deflected, 
transformed, or absorbed by the organization. The functional organization may consequently be understood as a buffer, channeling, portioning, and translating external requirements into internal working conditions. Deregulating the functional organization will, therefore, expose the individual to the complex and turbulent environment surrounding the organization. Deregulating the organization may of course be done for the very purpose of making the organization permeable to outside forces, in particular market forces, and subsequently to govern the individuals by way of these forces (du Gay, 1991; du Gay \& Salaman, 1992).

This brings us to the third type of rational which involves new instruments of governance. Parallel to the successive employment of flexible working conditions, there has been a corresponding development of management techniques that operate independently of the bureaucratic infrastructure. These techniques may or may not subscribe to the methods or philosophy of conventional managerial brand names, like Management by Objectives, Total Quality Management, or Human Resource Management. They all, however, involve a rationale for action and a subsequent evaluation of its outcome. The measurements of that outcome may, in turn, involve a straightforward economic balance sheet or an estimate of customer satisfaction. In either case, they fully rely on the individual having the requisites and maneuverability for achieving the stipulated outcome. Since these instruments of governance operate through the volition and ambition of individuals, they presuppose a certain freedom of action. They are in fact obstructed by the functional organization, with its bureaucratic forms of governance and passive work force. Instead, they thrive on competitiveness and entrepreneurship (du Gay et al., 1996; Rose, 1992, 1999).

As can be seen, deregulating work and thereby creating a weaker situation does not leave the individual in a regulatory vacuum. Suspending the unconditional rules of a bureaucratic organization will only shift the workers' attention to other more conditional rules. In other words, our instrument indirectly measures the proportion of two qualitatively different, and actually contradictory, forms of governance. On the one hand, there is the governance through general and unconditional regulations, whether in the shape of explicit rules, physical settings, or standardized operating procedures. This is a form of governance associated with industrialized production, a fragmented labor process, and a bureaucratic organization. On the other hand, there is the governance of self-regulation through, for instance, rational choice, prudent decisions, and attentive conduct. This is a form of governance associated with functional flexibility, decentralized accountability, and postbureaucratic organization. So, in effect, by directly demonstrating the prevalence of organizational regulation, the study also indirectly demonstrates the prevalence and diffusion of other and more indirect forms of governance.

The results show that almost half $(47 \%)$ of the jobs on the Swedish labor market can be characterized as low- or unregulated. This means that almost half of the Swedish work force is subjected to nonregulated working conditions or, what we have previously described, as a nonnegligible requirement for self-governing within their work. It also means that almost half of the Swedish work force is susceptible to a more indirect form of management that to a substantial degree leaves them accountable for their job.

Inversely, the results show that less than a sixth $(16 \%)$ of the jobs on the Swedish labor market are subjected to working conditions that may be characterized as traditional and fitting with an industrial model of work. This means that less than a sixth of the Swedish work force work under conditions that are presupposed by the welfare 
state and many of its administrative and organizing policies, like work environment measures, labor market programs, union affiliation, and social insurance benefits.

\section{References}

Anderson, G., Brosnan, P., \& Walsh, P. (1994). Flexibility, Casualization and Externalization in the New Zealand Workforce. Journal of Industrial Relations, 36(4), 491-518.

Appelbaum, E., \& Batt, R. (1994). The New American Workplace: Transforming Work Systems in the United States. Ithaca, NY: Cornell University Press.

Arthur, M. B. (1994). The Boundaryless Career: A New Perspective for Organizational Inquiry. Journal of Organizational Behaviour, 15(4), 295-306.

Arvidsson, N., \& Ekstedt, E. (2006). The Growth of Project Organisation and its Effects on Working Conditions. In J. Olofsson \& M. Zavisic (Eds.), Routes to a More Open Labour Market, The National Institute for Working Life Yearbook (pp. 88-102). Stockholm, Sweden: The National Institute for Working Life.

Atkinson, J. (1984). Flexibility, Uncertainty and Manpower Management. IMS Report, Institute of Manpower Studies.

Atkinson, J., \& Meager, N. (1986). Changing Working Patterns: How Companies Achieve Flexibility to Meet New Needs. Report for the National Economic Development Office, NEDO, Institute for Manpower Studies.

Bailey, D. E., \& Kurland, N. B. (2002). A Review of Telework Research: Findings, New Directions, and Lessons for the Study of Modern Work. Journal of Organizational Behavior, 23(4), 383-400.

Barley, S. R., \& Kunda, G. (2006). Gurus, Hired Guns, and Warm Bodies: Itinerant Experts in a Knowledge Economy. Princeton, NJ: Princeton University Press.

Becker, P. E., \& Moen, P. (1999). Scaling Back: Dual-Earner Couples’ Work-Family Strategies. Journal of Marriage and the Family, 61(4), 995-1007.

Bell, N. E., \& Staw, B. M. (1989). People as Sculptors versus Sculpture: The Roles of Personality and Personal Control in Organization. In M. B. Arthur, D. T. Hall, \& B. S. Lawrence (Eds.), Handbook of Career Theory. Cambridge: Cambridge University Press, pp. 232-251.

Briscoe, F. (2006). Temporal Flexibility and Careers: The Role of Large-Scale Organizations for Physicians. Industrial and Labor Relations Review, 60(1), 88-104.

Bruun, N., \& Johnson, M. (1995). The Legal and Contractual Situation of Teleworkers. Undersökningsrapport, National Institute for Working Life/Arbetslivsinstitutet.

Burchell, B. J., Ladipo, D., \& Wilkinson, F. (Eds.). (2002). Job Insecurity and Work Intensification. London: Routledge.

Burton-Jones, A. (1999). Knowledge Capitalism: Business, Work, and Learning in the New Economy. Oxford: Oxford University Press.

Carnoy, M., Castells, M., \& Benner, C. (1997). Labour Markets and Employment Practices in the Age of Flexibility: A Case Study of Silicon Valley. International Labour Review, 136(1), 27-48.

Cascio, W. F. (2000). Managing a Virtual Workplace. The Academy of Management Executive (1993), 14(3), 81-90.

Castells, M. (1996). The Information Age. Economy, Society and Culture. Volume 1: The Rise of the Network Society. Oxford: Blackwell.

Chapman, A. J., Sheehy, N. P., Heywood, S., Dooley, B., \& Collins, S. C. (1995). The Organizational Implications of Teleworking. International Review of Industrial and Organizational Psychology, 10, 229-248.

Cooper, C. D., \& Kurland, N. B. (2002). Telecommuting, Professional Isolation, and Employee Development in Public and Private Organizations. Journal of Organizational Behavior, 23(4), 511-532. 
Cortada, J. W. (Ed.). (1998). Rise of the Knowledge Worker. Boston, MA: ButterworthHeinemann.

Doyle, J. K., \& Ford, D. N. (1998). Mental Models Concepts for System Dynamics Research. System Dynamics Review, 14(1), 3-29.

Ekinsmyth, C. (2002). Project Organization, Embeddedness and Risk in Magazine Publishing. Regional Studies, 36(3), 229.

Ekstedt, E. (1999). Neo-Industrial Organising: Renewal by Action and Knowledge Formation in a Project-Intensive Economy. London: Routledge.

Furåker, B., Håkanson, K., \& Karlsson, J. C. (Eds.). (2007). Flexibility and Stability in Working Life. Basingstoke: Palgrave Macmillan.

du Gay, P. (1991). Enterprise Culture and the Ideology of Excellence. New Formations: A Journal of Culture, Theory, Politics, 13, 45-61.

du Gay, P. (1996). Consumption and Identity at Work. London: Sage.

du Gay, P., \& Salaman, G. (1992). The Cult(ure) of the Customer. Journal of Management Studies, 29(5), 615-633.

du Gay, P., Salaman, G., \& Rees, B. (1996). The Conduct of Management and the Management of Conduct: Contemporary Managerial Discourse and the Constitution of the "Competent" Manager. Journal of Management Studies, 33(3), 263-282.

Green, F., \& McIntosh, S. (2001). The Intensification of Work in Europe. Labour Economics, 8(2), 291-308.

Hacker, W. (1986). Arbeitspsychologie. Schriften zur arbeitspsychologie (Vol. 41). Stuttgart: Verlag Hans Huber.

Haddon, L. (1998). The Experience of Teleworking: A View from the Home. In P. J. Jackson \& J. M. van der Wielen (Eds.), Teleworking: International Perspectives. From Telecommuting to the Virtual Organisation. London: Routledge, pp. 136-143.

Hakim, C. (1990). Core and Periphery in Employers' Workforce Strategies: Evidence from the 1987 E.L.U.S. Survey. Work Employment Society, 4(2), 157-188.

Handy, C. B. (1984). The Future of Work: A Guide to a Changing Society. Oxford: Basil Blackwell.

Handy, C. B. (1989). The Age of Unreason. Boston, MA: Harvard Business School Press.

Harrison, B. (1994). Lean and Mean: The Changing Landscape of Corporate Power in the Age of Flexibility. New York, NY: Basic Books.

Harrison, B., \& Kelley, M. R. (1993). Outsourcing and the Search for "Flexibility". Work Employment Society, 7(2), 213-235.

Holman, D. (Ed.). (2003). The New Workplace: A Guide to the Human Impact of Modern Working Practices. Chichester: Wiley.

Hudson, M. (2002). Flexibility and the Reorganisation of Work. In B. Burchell, D. Ladipo, \& F. Wilkinson (Eds.), Job Insecurity and Work Intensification. London: Routledge, pp. 39-60.

Jackson, P. J., \& van der Wielen, J. M. (Eds.). (1998). Teleworking: International Perspectives. From Telecommuting to the Virtual Organisation. London: Routledge.

Jacobs, J. A., \& Gerson, K. (2001). Overworked Individuals or Overworked Families?: Explaining Trends in Work, Leisure, and Family Time. Work and Occupations, 28(1), 40-63.

Jones, C. (1969). Careers in Project Networks: The Case of the Film Industry. In M. B. Arthur \& D. M. Rousseau (Eds.), The Boundaryless Career: A New Employment Principle for a New Organizational Era (pp. 58-75). Oxford: Oxford University Press.

Kalleberg, A. L. (2001). Organizing Flexibility: The Flexible Firm in a New Century. British Journal of Industrial Relations, 39(4), 479-504.

Kalleberg, A. L., Rasell, E., Cassirer, N., Reskin, B. F., Hudson, K., Webster, D., et al. (1997). Nonstandard Work, Substandard Jobs: Flexible Work Arrangements in the U.S. Washington, D.C.: Economic Policy Institute. 
Kanter, R. M. (1983). The Change Masters: Innovation for Productivity in the American Corporation. New York, NY: Simon and Schuster.

Kanter, R. M. (1989). When Giants Learn to Dance: Mastering the Challenges of Strategy, Management, and Careers in the 1990s. London: Simon \& Schuster.

Karasek, R., \& Theorell, T. (1990). Healthy Work. New York, NY: Basic Books.

Katz, D., \& Kahn, R. L. (1978). The Social Psychology of Organizations (2nd edn.). New York, NY: Wiley.

Kelliher, C., \& Riley, M. (2003). Beyond Efficiency: Some By-products of Functional Flexibility. Service Industries Journal, 23(4), 98-113.

Legge, K. (2005). Human Resource Management: Rhetorics and Realities (Anniversary Edition). Houndmills, Basingstoke, Hampshire: Palgrave Macmillan.

Lundin, R. A., \& Söderholm, A. (1995). A Theory of the Temporary Organization. Scandinavian Journal of Management, 11(4), 437-455.

March, J. G. (1978). Bounded Rationality, Ambiguity, and the Engineering of Choice. The Bell Journal of Economics, 9(2), 587-608.

Midler, C. (1995). "Projectification" of the Firm: The Renault Case. Scandinavian Journal of Management, 11(4), 363-375.

Mirchandani, K. (1998). Protecting the Boundary: Teleworker Insights on the Expansive Concept of "Work". Gender Society, 12(2), 168-187.

Mischel, W. (1977). The Interaction of Person and Situation. In D. Magnusson \& Endler (Eds.), Personality at the Crossroads: Current Issues in Interactional Psychology. Hillsdale, NJ: Erlbaum, pp. 333-352.

Neff, G., Wissinger, E., \& Zukin, S. (2005). Entrepreneurial Labor among Cultural Producers: "Cool" Jobs in "Hot" Industries. Social Semiotics, 15(3), 307.

OECD. (1998). OECD Employment Outlook. Organisation for Economic Co-operation and Development.

OECD. (2008). Labour Force Statistics: 1986-2006 (p. 482). Geneva: Organisation for Economic Co-operation and Development.

Osterman, P. (1994). How Common is Workplace Transformation and Who Adopts It? Industrial \& Labor Relations Review, 47(2), 173-188.

Paganetto, L. (2004). Knowledge Economy, Information Technologies and Growth. Aldershot: Ashgate.

Peters, T. J., \& Waterman, R. H. J. (1982). In Search of Excellence: Lessons from America's Best-run Companies. New York, NY: Harper \& Row.

Pollert, A. (Ed.). (1991). Farewell to Flexibility? Oxford: Blackwell.

Powell, W. W. (2001). A New Logic of Organizing: Causes and Processes of Diffusion. Studia oeconomiae negotiorum (p. 53). Uppsala: Acta Universitatis Upsaliensis.

Powell, W. W., \& Snellman, K. (2004). The Knowledge Economy. Annual Review of Sociology, 30(1), 199-220.

Procter, S. J., Rowlinson, M., McArdle, L., Hassard, J., \& Forrester, P. (1994). Flexibility, Politics \& Strategy: In Defence of the Model of the Flexible Firm. Work Employment Society, 8(2), 221-242.

Qvortrup, L. (1998). From Teleworking to Networking: Definitions and Trends. In P. J. Jackson \& J. M. van der Wielen (Eds.), Teleworking: International Perspectives. From Telecommuting to the Virtual Organisation. London: Routledge, pp. 21-39.

Rasmussen, J. (1986). Information Processing and Human-Machine Interaction: An Approach to Cognitive Engineering. System Science and Engineering (Vol. 12). Amsterdam: North-Holland.

Rose, N. (1992). Governing the Enterprising Self. In P. Heelas \& P. Morris (Eds.), The Values of the Enterprise Culture: The Moral Debate (pp. 141-163). London: Routledge.

Rose, N. (1999). Powers of Freedom: Reframing Political Thought. Cambridge: Cambridge University Press. 
Saloniemi, A., \& Zeytinoglu, I. U. (2007). Achieving Flexibility through Insecurity: A Comparison of Work Environments in Fixed-term and Permanent Jobs in Finland and Canada. European Journal of Industrial Relations, 13(1), 109-128.

Saxenian, A. (1996). Beyond Boundaries: Open Labor Markets and Learning in Silicon Valley. In M. B. Arthur \& D. M. Rousseau (Eds.), The Boundaryless Career: A New Employment Principle for a New Organizational Era. Oxford: Oxford University Press, pp. 23-39.

SCB. (2008). The Occupational Structure in Sweden 2006-Occupational Statistics based on the Swedish Occupational Register. Yrkesregistret med yrkesstatistik, Statistics Sweden.

Schieman, S., Whitestone, Y. K., \& Van Gundy, K. (2006). The Nature of Work and the Stress of Higher Status. Journal of Health and Social Behavior, 47, 242-257.

Sennett, R. (1998). The Corrosion of Character: The Personal Consequences of Work in the New Capitalism. New York, NY: Norton.

Storper, M. (1994). The Transition to Flexible Specialisation in the US Film Industry: External Economies, the Division of Labour and the Crossing of Industrial Divides. In A. Amin (Ed.), Post-Fordism: A Reader. Oxford: Blackwell, pp. 195-226.

Vallas, S. P., \& Beck, J. P. (1996). Transformation of Work Revisited: The Limits of Flexibility in American Manufacturing. Social Problems, 43(3), 339-361.

Weick, K. E. (1995). Sensemaking in Organizations. Foundations for Organizational Science. Thousand Oaks, CA: Sage Publications.

Weick, K. E. (1996). Enactment and the Boundaryless Career: Organizing as We Work. In M. B. Arthur \& D. M. Rousseau (Eds.), The Boundaryless Career: A New Employment Principle for a New Organizational Era. Oxford: Oxford University Press, pp. 40-57.

Wood, S. (Ed.). (1989). The Transformation of Work. London: Unwin Hyman Ltd.

\section{End notes}

${ }_{1}$ The deviating response pattern within the performance dimension is, we suspect, due to respondents confusing the demand for individual versus collective planning within their job. Most jobs involve the participation in some kind of joint planning meeting. These meetings may be more or less mandatory, more or less frequent, and more or less common. Still, the pronounced intention is the participation in the planning of work. It is, again we suspect, their required participation in such meetings that they refer to when claiming that their job presupposes active planning on their part. 